See discussions, stats, and author profiles for this publication at: https://www.researchgate.net/publication/322298170

\title{
Del mito al resignificación del paisaje urbano: La representación literaria de la Atenas Suramericana
}

Working Paper · January 2018

CITATIONS

0

1 author:

Universitaria uniagustiniana

71 PUBLICATIONS 65 CITATIONS

SEE PROFILE

Some of the authors of this publication are also working on these related projects:

Gabo y la ciudad de los poetas: Hacia el reconocimiento de Bogotá como ciudad literaria View project

Prácticas Pedagógicas y Didácticas View project
READS

31 


\title{
Del mito al resignificación del paisaje urbano: La representación literaria de la Atenas Suramericana
}

\author{
Fabián Andrés Llano (1) \\ (1) Universidad La Gran Colombia y Corporación Unificada Nacional de Educación \\ Superior CUN. Carrera 5 №62-20 Bogotá, Colombia. fabian Ilano@cun.edu.co; \\ Ilanofabian@hotmail.com; ID 0000-0003-2181-3476
}

\section{Resumen}

El presente texto hace parte de la propuesta para participar en el Congreso Iberoamericano "Patrimonio, sus materias e inmaterias". El escrito parte de la preocupación por entender los procesos de configuración del Patrimonio Cultural de la ciudad de Bogotá en relación al uso correcto del lenguaje, en una época de gran versatilidad intelectual conocida en América Latina, como "la Atenas suramericana" ". Rastrear el cambio de siglo XIX al XX a propósito de uno de los grandes mitos lingüísticos de América Latina, supone un acercamiento detallado a los procesos de construcción de repertorios lingüísticos, legitimación cultural y revalidación de fuentes primarias que logren aclarar este inacabado proceso de modernización cultural en un país como Colombia.

La Bogotá de los gramáticos, poetas y filólogos, junto con las referencias al uso del mejor castellano por parte de algunos representantes del interior del país como Miguel Antonio Caro y Rufino José Cuervo, permiten seguir los indicios y las huellas lingüísticas, sociales y culturales que esta época dejó con el fin de rastrear los procesos de construcción de una identidad cultural y el resignificación del paisaje urbano en Bogotá. Seguir los rastros de esta embrionaria historia literaria y las formas de producción cultural bajo los cambios materiales y simbólicos de la ciudad permite enlazar estos rastros de la historia para

\footnotetext{
1 El apelativo de Atenas suramericana, Atenas del sur o "la ciudad del águila negra", para referirse a la cultura literaria de la ciudad de Bogotá se le endilga al geógrafo francés Eliceo Reclus quien visito Colombia a mediados del siglo XIX. Además de esta referencia a los orígenes de la denominación apareció otra en Madrid, España de 1893 a 1895, con la publicación antología de poetas hispanoamericanos por Marcelino Menéndez Pelayo, donde caracteriza la cultura literaria de Santa fé de Bogotá como la Atenas de la América del sur (Montenegro, 2003)
} 
recomponer una imagen de la Bogotá culta y al mismo tiempo evidenciar las carencias y la miseria de esta ciudad en su proceso de modernización.

Palabras clave: Patrimonio cultural, legitimación cultural, identidad cultural, producción cultural.

\section{Presentación}

El siguiente texto parte de la preocupación por entender las relaciones, las dislocaciones y las tensiones culturales que se presentaron entre unos procesos de configuración del Patrimonio y la identidad Cultural en la Bogotá de finales del siglo XIX y las tres primeras décadas del XX. Esta defensa de unos valores tradicionales que representaban un modo de vida hispánico bajo el predominio de un modelo colonial se enfrentó a unos nuevos escenarios de sociabilidad y encuentro, como los cafés de la ciudad de Bogotá entre 1880 y 1930. Al convivir con escenarios coloniales y formas tradicionales de conservación de la cultura, los nuevos lugares para la sociabilidad, como clubes, salones, hoteles y cafés se abrieron paso dentro de la fisionomía colonial para buscar imponer unos sentidos de lo moderno basados en una civilización de la palabra².

\section{El poder, las letras y la transformación urbana de Bogotá}

Romper con el orden colonial y buscar la modernización y el modernismo cultural resultó un complejo proyecto compartido por diferentes facciones políticas que se debatían en torno a la legitimación de una identidad cultural, un proyecto de ciudad y un deseo de modernidad. Vale la pena aclarar que estos procesos de configuración de la identidad cultural se afianzaron desde sus modos más tradicionales, desde la erudición, la conservación de las formas clásicas del lenguaje y una conexión con el pasado español

\footnotetext{
${ }^{2}$ Según Monterde (2009) los cafés en Europa se convirtieron en espacios de la modernidad literaria, en unos espacios propensos a la existencia y opinión pública, por tanto, se constituyeron en un punto clave en los procesos de secularización. Tal cual como estaba ocurriendo en Europa, la elite bogotana, que había visitado diferentes partes de Europa, esperaban una vuelta de tuerca en la dinámica cultural de una ciudad como Bogotá. Con estos espacios modernos y unas ideas democráticas de la cultura, se esperaba una secularización de la sociedad. Este debate entre lo antiguo y lo moderno, que desde el siglo XVIII se venía presentando en Francia con el posicionamiento de una ética ligada a los valores laicos y el desarrollo de la ciencia que logró dimensionar al hombre como sujeto de la historia, se esperaba un deslinde con los valores y la simbolización cristiana en la subjetividad del hombre antiguo.
} 
con una relación estrecha con el uso correcto del lenguaje y con un proyecto político denominado "la regeneración".

Lo interesante de este periodo denominado por la historiografía colombiana como la época de la regeneración y la República conservadora, es la creciente preocupación y respeto por las formas correctas del idioma. Según Malcom Deas (1993) diferentes escritores, novelistas y poetas ejercieron la política en cargos como congresistas, ministros y hasta presidentes de la República desde finales del siglo XIX hasta la tercera década del siglo XX. En efecto, la prominencia de gramáticos y filólogos en la vida política del país, se puede evidenciar en la producción lingüística de diccionarios y obras asociadas con el lenguaje, donde se postulan como los más aceptados y representativos a Rufino José Cuervo y Miguel Antonio Caro. Pero ¿qué caracterizó a estos personajes tan representativos de la vida nacional? Un punto importante que sostiene Deas (1993) es el origen cultural y social de estos hombres prolíficos, donde el linaje no está asociado con la acumulación de riquezas sino con el fortalecimiento de las letras a través de la educación.

Así, esta práctica lingüística, que según Jaramillo (1998) se caracterizó por la conversación, la lectura en voz alta y la recitación, tuvo un desarrollo en medio de las transformaciones económicas, sociales y culturales de la ciudad, donde no solamente se buscaba la proyección de una imagen erudita de la ciudad conocida como la Atenas Suramericana para hacerle frente a la naciente burguesía bogotana, sino que por medio de la censura, el insulto, la descalificación y la clasificación social, los letrados intentaron transgredir estos cambios mediante la imposición de criterios coloniales como la limpieza de sangre, el orgullo de linaje, y el prejuicio social, convirtiendo el uso correcto del lenguaje en un mecanismo para impedir el cambio y suprimir otras identidades culturales que intentaban posicionarse en la ciudad (Llano, 2012) Como se puede deducir, el establecimiento de sociedades, academias y fundaciones fue otra de las estrategias adoptadas para que las clases altas impusieran su estilo de vida (Mejía: 1999 p 37). Estas estaban conformadas por hombres reconocidos en el ámbito social y cultural de la ciudad denominada en algunos países de Latinoamérica como "la Atenas suramericana"

Estas formas clásicas de legitimación de la cultura, estaban lideradas por un grupo de eruditos asociados al poder político: Los letrados. Esta identidad dominante buscó fortalecer un proyecto cultural que asumió como requisito de distinción la herencia 
idiomática y la conexión con el pasado español a través de unas formas de moral y de modal que no sólo afianzaron la adscripción a una comunidad política, sino que a través de la educación y las buenas maneras persiguió un tipo de modernidad cultural frente a la influencia de una parte de la élite bogotana, que privilegió los desarrollos materiales (Llano,2012).

A partir de la segunda década del siglo $X X$, se hace evidente en Bogotá una transformación en el proyecto ciudadano de la época. Emerge una ciudadanía nacional, propulsada por las élites Bogotanas, quienes, por los efectos benévolos de la economía nacional, producto de la indemnización de panamá y los ciclos extractivos del café, se vieron beneficiados de manera notable al consolidar la actividad económica industrial y comercial en la ciudad ${ }^{3}$. Con una necesidad de quebrar las viejas formas culturales y alejarse de la ciudad monacal del siglo XIX, se plantea la adopción del paradigma de la modernidad. Frente a una ciudad con pocas posibilidades de crecimiento, que más que fortalecer la sociabilidad pública y los encuentros ciudadanos promoviendo nuevos espacios para la diversión, la conversación y la vida pública, se había centrado en fortalecer la diferenciación social en lugares privados y en la cercanía espacial que lograba una ciudad pequeña, los nuevos sentidos de la existencia que provenían de aquella experiencia moderna en ciudades como Paris y Londres, se habían constituido en fuertes referentes culturales a seguir 4 .

De este modo se hacía necesaria una reorganización del espacio urbano, para esta época, en torno a los discursos de la higiene, en medio de un universo social caritativista que va a re disponer los espacios de la ciudad, para que se corresponda con la nueva

\footnotetext{
${ }^{3}$ Entre calificativos como impúdico brebaje o tinta de uvilla con tártaro, el café fue denigrado por José María Vergara y Vergara hombre de letras y fundador de la Academia Colombiana de la Lengua (1872) Esta bebida era tenida en cuenta solo una moda extranjera que podía trastocar los valores y los sentidos de lo clásico representado en una bebida como el chocolate. Estas denuncias de Vergara y Vergara, en su escrito las tres tazas anticipaban un poco los cambios culturales que se harían evidentes a finales del siglo XIX y comienzos del XX Mas allá de una convicción por chocolate, lo que denuncia Vergara y Vergara en 1866 es la pretensión de Juan de Viñas de aparentar lo que no tenía y lo que no era. Este anfitrión invitó a sus amigos a tomar café, solo porque era una bebida de moda; pero lo más grave era que había gastado una fortuna en ello.

${ }^{4}$ La modernidad como experiencia del tiempo y del espacio bajo la estructuración del modernismo y la modernización proyectó imágenes intensas, extravagantes abismos, terremotos, ruptura con la tradición, en fin, un sin número de contradicciones que se convirtieron en una nueva forma de vida, una nueva identidad que concreto en la vida urbana. Marshall Berman (1991) lo ilustra a través de la novela romántica de Rousseau "la nueva Eloísa" Saint Preux capta esta nueva experiencia moderna en la agitación de la ciudad, en la destrucción de las barreras morales y los vínculos personales, en la expansión y desarreglos de la personalidad, en últimas, capta la atmosfera de la sensibilidad moderna(p4)
} 
imagen de los grupos dominantes. Lo que, si era claro para esta época, era el afán de modernización, no solo económica sino cultural, en donde la élite aristocrática, instrumentalizó la cultura para dirigir el rumbo de la sociedad hacia lo que la élite consideraba civilización, y dejar atrás lo que entendían por barbarie: hablar y vestirse mal y tener un comportamiento ajeno a las reglas dictadas por los manuales de urbanidad (Zambrano, 2003, p119).

No obstante, estas influencias extranjeras presentes en la construcción de un nuevo Estado y un proyecto de nación se evidencian con claridad al momento de una incorporación de formas y representaciones sociales ligadas a la modernización del país. Este cambio de un sistema colonial a la lógica del lucro y la renta propios de un sistema capitalista, se logró gracias a una transformación de la lógica económica que pasó de la explotación de la tierra de los grandes terratenientes a nuevas estructuraciones económicas que quebraron el modelo económico colonial al finalizar el siglo XIX. De este modo, un deseo de modernidad estuvo presente en la elite del país alrededor de un proyecto de ciudad muy al estilo de algunas ciudades europeas como Paris y Londres y el fuerte paradigma estadunidense, que bajo los grandes rascacielos de Nueva York marcaron una tendencia en la arquitectura y en la difusión de un estilo de vida cosmopolita (Serna, 2001; Pérgolis, 2013) ${ }^{5}$.

De esta manera, los gustos y los sentidos de la existencia se debatieron entre lo tradicional y lo novedoso, entre la incorporación de lo universal en la vida de la ciudad y el mantenimiento de las tradiciones. De esta forma, la estrategia cultural utilizada por las élites, consistió en resaltar unos estilos de vida como forma legítima de la existencia en la ciudad. Escenarios como el cine, los cafés, el teatro y las exposiciones de pintura, se convierten en lugares propicios para mostrar el lujo y la ostentación, como beneficios inexpugnables del avance de la civilización (Chavarro, C. \& Llano, F. 2010).

\footnotetext{
${ }^{5}$ Las imágenes de la ensoñación modernista de los bogotanos se concretaron lentamente desde el inicio de la construcción del Capitolio Nacional a mediados del siglo XIX hasta 1926, cuando la remodelación de la Plaza de Bolívar, obra de Alberto Manrique Martín, definió la imagen del centro de la ciudad (...)en el caso de Medellín, el paradigma fue Nueva York y, el centro de Medellín a través de esas imágenes se renovó, no con los rascacielos -imposibles cuando los materiales de construcción dependían del transporte en mulas- sino con los edificios de fachadas continuas con vitrinas comerciales en el primer piso y vivienda en los pisos altos. Del deseo de modernidad en Cartagena y Barranquilla permitió ver las dos caras de un mismo anhelo: mientras en Cartagena el deseo de recuperación de anteriores momentos abrió las puertas a una modernidad que se concentró en una parte de la ciudad (en torno al Camellón de los Mártires y el Parque Centenario), en Barranquilla la modernidad se expresó a través de la movilidad y el transporte (Pérgolis 2011, 227,228).
} 


\section{Los nuevos sentidos de la existencia y las sobrevivencias literarias}

En este anudamiento para la consolidación de una identidad cultural, termino por vincular la tradición, las formas clásicas en el uso del lenguaje conservar y los nuevos sentidos de la existencia. Bajo tal contexto, la élite Bogotana propugnó por encumbrar unas formas de ciudad y ciudadanía que tenía en medio el discurso civilizatorio y del progreso, imitando, de alguna forma, a las metrópolis europeas. Como en el reconocimiento del hombre en un espejo, la élite bogotana buscó los referentes propios de su imagen, en la imagen de otros. No obstante, es importante tener en cuenta que la ciudad adquiere sentido cuando es capaz de satisfacer el deseo de sus habitantes, un deseo de modernidad que supone una historia y que además se satisface cuando se produce un acontecimiento (Pérgolis, 2000). Con una idea de ciudades civilizadas y unas historias sobre la estética, el gusto, y las buenas maneras afianzadas desde la literatura europea, la elite bogotana se acercó a un proyecto cultural que tenía en medio los trasuntos coloniales.

Estos modos entusiastas de representación sobre lo moderno que incluía la transformación de la ciudad desde sus espacios físicos para dotar a Bogotá de un mobiliario urbano en su apertura pública y cuya proyección ideal buscaba la inclusión y la aceptación de formas de contravención cultural como la bohemia, las revistas literarias, los cafés y los cabarets; chocaron con otras formas de representación de lo moderno caracterizado por el apego a las formas clásicas y tradicionales representadas en la idea de Bogotá como la Atenas de América del sur.

En un cambio de época donde sobrevivían formas coloniales en las costumbres, en la arquitectura y en la literatura, los anacronismos y las supervivencias convivieron con algunas formas renovadas de la cultura como la influencia de las vanguardias europeas y el simbolismo francés. Este acontecimiento de ser modernos y el deseo de consolidar unos estilos de vida deseables en la ciudad, además de los significados en la moda y en el consumo cultural, requería de unos espacios físicos y lugares de encuentro que se inscribieron en las transformaciones de la estructura urbana colonial. En efecto, estos nuevos lugares de intercambio lingüístico, artístico, de producción cultural y sobre todo de diferenciación social, fortalecerá una cultura de la conversación y unos espacios de producción de pensamiento para la elite bogotana, que buscaba en el cambio de siglo y las 
primeras décadas del XX un distanciamiento con las formas clásicas de legitimación de la cultura.

Estos nuevos espacios con pretensiones de una modernidad europea, se desarrollaron dentro de una escenografía tradicional que albergaba viejos caserones coloniales, iglesias y algunos atisbos de arquitectura moderna. La expansión de la trama urbana desde el centro de la ciudad hacia chapinero y los barrios obreros convivieron con antiguos caserones coloniales y los esquemas simbólicos de una ciudad centrada en lo conventual y en la organización espacial por parroquias.

Finalmente, una demanda creciente de espacios para concretar los sentidos de la modernidad, como los cafés, se hicieron cada vez más necesarios en la medida en que la capital se consolidaba como centro financiero producto de una industrialización que en el país empezaba a concretarse ${ }^{6}$. A pesar de este desarrollo económico que se correspondía con una satisfacción de ser modernos y una demanda creciente de concretar un orden simbólico en la ciudad, supervivían unas formas tradicionales de conservación cultural que propendían por una conexión con España y una necesidad creciente de una historia literaria para soportar la identidad nacional del país.

En este proceso de transición de una sociedad colonial a una sociedad moderna, los cafés en la ciudad marcaron los primeros desplazamientos de los lugares de encuentro de la elite bogotana. Se pasaba de las prácticas de la conversación en el altozano, a los encuentros literarios del café "la Botella de oro", ubicado en el mismo lugar del atrio de la catedral. De los peripatéticos letrados que circulaban y conversaban en el terraplén de la Catedral sosteniendo conversaciones elevadas muy al estilo de los grandes filósofos griegos, se pasaba a los encuentros de los habitantes en el café ubicado en el mismo lugar donde acontecía la vida política y literaria de la ciudad.

\section{Referencias}

\footnotetext{
${ }^{6}$ Según Melo (1991) durante la segunda y tercera décadas del siglo XX un nuevo crecimiento exportador contribuyó a consolidar definitivamente las bases para el desarrollo capitalista en el país y para su definitiva incorporación en la economía mundial. El café, cultivado sobre todo por campesinos independientes, había contribuido apoyando una transformación general de la economía del país (p.236)
} 
Berman, M (1988). Todo lo solido se desvanece en el aire. La experiencia de la modernidad. Editorial siglo veintiuno, Bogotá Colombia

Chavarro, C. \& Llano, F. (2010). El héroe, el lujo y la precariedad patrimonio histórico en Bogotá (1880-1950). Bogotá: Universidad La Gran Colombia.

Deas, M. [1993] Del poder y la gramática y otros ensayos sobre historia política y literatura colombiana; Miguel Antonio Caro y sus amigos: gramática y poder en Colombia. Bogotá: tercer mundo editores.

Jaramillo. E. (1998) Artes de la Lectura en la Ciudad del Águila Negra: La Lectura en voz alta y la recitación en Santafé de Bogotá a fines del siglo XIX. Revista Iberoamericana. Vol. XIV. Nums. 184-185

Llano, F (2014) espacios olvidados, lugares diferenciados: transformación social del espacio urbano en Bogotá (1850- 1880) Revista Nodo Universidad Antonio Nariño

Llano, F. (2012). Caro, Cuervo y la resistencia lingüística. Construcción de la identidad ciudadana, desde el uso de la lengua. Bogotá (1880-1950). Bogotá: Universidad La Gran Colombia.

Mejía, G. (1999) Los años del cambio. Historia urbana de Bogotá (1820-1910) pontificia Universidad Javeriana Facultad de Ciencias Sociales.

Melo, J. [1991]. La República conservadora. En Colombia Hoy perspectivas hacia el siglo XXI. Siglo XXI editores. Bogotá

Montenegro, A. (2003) La Atenas suramericana. Búsqueda de los orígenes de la denominación dada a Bogotá. Revista memoria y sociedad Vol. 7 N 14 abril pp133-143. XX.

Monterde A. (2009) Poética del Café, un espacio de la modernidad literaria europea. Anagrama colección argumentos, Barcelona 
Pérgolis J. (2000) Estación plaza de Bolívar una mirada desde la semiótica del deseo a la ciudad y su plaza, Alcaldía Mayor de Bogotá, Instituto Distrital de Cultura y Turismo

Pérgolis, J. (2011) Ciudad republicana y deseo de modernidad en: Revista Módulo / Volumen 1, Número 10 / Julio / Barranquilla, Colombia / ISSN 0124-6542

Pérgolis, J. (2013) El deseo de modernidad en la ciudad republicana, Editorial: U. Católica de Colombia

Serna A. (2001) Próceres, textos y monumentos: culturas urbanas, discursos escolares y formas de la historia: Bogotá (1938- 1991) Univ. Del bosque facultad de educación. Documento inédito

Zambrano, F. [2003]. La transición al siglo xx: la prensa durante la hegemonía conservadora, en medios y nación, historia de los medios de comunicación en Colombia. Ministerio de cultura, Colombia, 